\title{
Ophthalmology Medical Student Directors, Associate Residency Program Directors, and Program Directors: A Benchmarking Study of Work and Life Metrics
}

\author{
Lora R. Dagi Glass, MD $\quad$ C. Gustavo De Moraes, MD, MPH, $\mathrm{PhD}^{1}$ Melissa A. Wright, $\mathrm{PhD}^{2}$ \\ Bryan J. Winn, MD ${ }^{3,4}$ Royce W. S. Chen, MD $^{1}$ George A. Cioffi, MD ${ }^{1}$
}

\footnotetext{
${ }^{1}$ Department of Ophthalmology, Edward S. Harkness Eye Institute, Columbia University Irving Medical Center, New York, New York

${ }^{2}$ Center for Teaching and Learning, Columbia University, New York, New York

${ }^{3}$ Department of Ophthalmology, University of California San

Francisco, San Francisco, California

${ }^{4}$ Ophthalmology Section, Surgical Service, San Francisco Veterans

Affairs Medical Center, San Francisco, California
}

\begin{abstract}
Address for correspondence Lora R. Dagi Glass, MD, Edward S. Harkness Eye Institute, 635 W. $165^{\text {th }}$ St, P.O. Box 77, New York, NY 10032 (e-mail: Id2514@cumc.columbia.edu).
\end{abstract}

J Acad Ophthalmol 2022;14:e23-e30.
Abstract
Keywords
- medical student director
- associate program director
- program director
- benchmark
- work metric
- life metric

Introduction During a time of increased interest in physician well-being, this study benchmarks current work life, home life, and burnout scores for ophthalmology medical student directors (MSD), associate program directors (APD), and program directors (PD).

Methods An anonymous cross-sectional survey was disseminated through the Association of University Professors of Ophthalmology (AUPO) listserve, with queries regarding leadership positions, work time allotment, extracurricular activities, family life, and burnout. Answers were analyzed descriptively through Fisher's exact test, Kruskal-Wallis test, and Poisson regression models.

Results Nineteen percent of listed MSD, 15\% of APD, and 29\% of PD queried responded to the survey. MSD, APD, and PD are statistically similar in terms of work and home life, with the exception of time spent performing administrative tasks for the position. PD spend more time on administrative tasks, and are paid more. All groups score positively on burnout surveys.

Conclusion This benchmarking survey demonstrates that MSD, APD, and PD are intensively involved in both their work and home lives, with a seemingly high correlation of sense of worth both personally and in their careers.

This cross-sectional, anonymous benchmarking survey of medical student directors (MSD), associate program directors (APD), and program directors (PD) provides a clear marker of work responsibilities, extracurricular activities, family life, and burnout.

Within academic ophthalmology, MSD, APD, and residency PD help shape curricular decisions, educational

received

January 20, 2021

accepted after revision

October 12, 2021
DOI https://doi.org/

$10.1055 / \mathrm{s}-0041-1741460$.

ISSN 2475-4757. goals, evaluations, mentorship, and future directions under the supervision of their respective medical schools and departments, with all parties working to ensure compliance with national accreditation bodies.

During a time of increased emphasis on trainee wellbeing-now a priority for the Accreditation Council for Graduate Medical Education (ACGME) and the Association (c) 2022. The Author(s).

This is an open access article published by Thieme under the terms of the Creative Commons Attribution-NonDerivative-NonCommercial-License, permitting copying and reproduction so long as the original work is given appropriate credit. Contents may not be used for commercial purposes, or adapted, remixed, transformed or built upon. (https://creativecommons.org/ licenses/by-nc-nd/4.0/)

Thieme Medical Publishers, Inc., 333 Seventh Avenue, 18th Floor, New York, NY 10001, USA 
of American Medical Colleges (AAMC)-there is an increased interest in physician well-being at large. An inverse marker of well-being is the concept of "burnout." Though burnout is subject to and suffers from multiple definitions, it is defined in the International Classification of Diseases, 11th revision as an occupational phenomenon, a syndrome of chronic work stress causing professional dysfunction, negativity, mental distancing, and fatigue. ${ }^{1}$ Whether reported subjectively or objectively, burnout is a problem for ophthalmologists both nationally and abroad. $^{2-5}$ Since MSD, APD, and PD guide the development of well-being curricula and evaluate trainees for the same, the current state of educational leadership well-being is important to understand.

This anonymous, cross-sectional, survey-based study provides a benchmark of work life, home life, and burnout metrics of MSD, APD, and PD members of the Association of University Professors of Ophthalmology (AUPO).

\section{Methods}

Research was performed with approval of the Columbia University Institutional Review Board. In conjunction with the Columbia Center for Teaching and Learning (CTL), a benchmarking survey was created (-Fig. 1) and approved by the AUPO. As the benchmarking survey incorporated the full Maslach Burnout Inventory for Educators (MBI), rights of distribution were approved by and purchased from Mind Garden, Inc. (www.mindgarden.com). The survey was then sent to all ophthalmology MSD, APD, and PD on the AUPO listserve with an initial email and three reminders over a 2week period (initial distribution 4/30/2019). Responses were collected in an anonymous fashion.

To maintain anonymity in a small educational leadership community, questions regarding age, gender, race, academic rank, geographic region, and number of medical students or residents were not queried.

Categorical variables are described as proportions and were tested with Fisher's exact test. Continuous variables are summarized with median and interquartile (25th to 75th percentiles) ranges and were tested with the Kruskal-Wallis test. Poisson regression models were used to test for the relationship between groups and scores for the CTL and MBI surveys. Computerized analyses were performed with STATA (version 14.2, StataCorp, Inc., 4905 Lakeway Dr, College Station, TX, www.stata.com). Statistical significance was defined at $p<5 \%$.

\section{Results}

Of 222 total listed MSD $(n=67)$, APD $(n=46)$, and PD $(n=109)$ on the AUPO listserve, 48 completed surveys were received (22\%). There were no incomplete surveys. Of the 48 responders, 13 served as MSD (27\%), 7 as APD (15\%), and 32 as PD (67\%). This accounted for 19\% of listed MSD, 15\% of APD, and $29 \%$ of PD queried. Three responders held positions as both MSD and $\mathrm{PD}$; 1 responder served both as MSD and APD. Of note, the AUPO listserve only allows for a single listed position; joint positions were uncovered by the survey.

Please see - Tables $\mathbf{1}$ and $\mathbf{2}$ for a summary of results.

\section{Work Benchmarks}

\section{Duration of Service}

The median MSD duration of service is 6 years (interquartile range: $2.5-8.5)$. The median APD service is 3 years (1-3). The median PD service is 5 years (3-12). There was a nonsignificant trend for greater number of years served as $\operatorname{PD}(p=0.1)$.

\section{Program Coordinator Support}

Program coordinators work with $85 \%$ of MSD, $71 \%$ of APD, and $100 \%$ of PD. Due to survey anonymity, it is not possible to discern whether an APD and PD from the same program were replying to this question.

For those MSD with a program coordinator, meetings are most often held weekly (31\%), as opposed to biweekly (15\%) or monthly (15\%), though there is a wide range with some meeting daily and others meeting variably depending on the time of year. Seventy-three percent are very satisfied with their program coordinator, with the remainder moderately satisfied.

For those APD with a program coordinator, meetings are most often held biweekly (43\%), with the remainder meeting weekly or monthly (14\% each, respectively). Sixty percent are very satisfied with their program coordinator, $20 \%$ moderately satisfied, and $20 \%$ very dissatisfied.

For PD, the majority meet with a program coordinator weekly (47\%), as opposed to daily (22\%), twice weekly (3\%), biweekly (16\%), or monthly (13\%). Fifty-three percent are very satisfied, $16 \%$ moderately satisfied, $6 \%$ neutral, $16 \%$ moderately dissatisfied, and $6 \%$ very dissatisfied with their program coordinator.

\section{Allocation of Workhours}

In terms of monthly administrative time directed toward the position, the median spent by an MSD is 10 hours (4-15), an APD 15 (10-20), and a PD 30 (20-40); PD spend more time on administrative duties than APD and MSD $(p=0.0008)$.

In a typical week, an MSD spends a median of 22.5 hours (20-30) on direct patient care, an APD 22.5 (10-30), and a PD 20 (10-25). An MSD spends a median of 7 hours (5-8) on procedures and surgery, an APD 8 (5-15), and a PD 8 (4.5-11). An MSD spends a median of 10 hours (10-20) on direct resident supervision, an APD 30 (16-30), and a PD 15 (722). An MSD spends a median of 8 hours (8-10) on administrative tasks, an APD 6 (5-10), and a PD 10 (7-18). An MSD spends a median of 2 hours (2-4) on other nonadministrative, nonclinical tasks (i.e., research), an APD 3 hours (1-5), and a PD 2 hours (1-5). There is no statistically significant difference in any of these time allotments between groups. Combining all three groups, 65\% take home clinical work, spending on average 4 hours weekly at home on clinical tasks, and $79 \%$ take administrative work home to complete, spending on average 5 weekly hours at home on administrative tasks (-Fig. 2). 
Survey Questions:

1. Which of the positions do you currently hold (check all that apply)?

a. Program Director (PD)

b. Assistant/Associate Program Director (APD)

c. Medical Student Director (MSD)

2. How many years have you been a (PD, APD, MSD)?

3. If you have a program coordinator for your function as a (PD, APD, MSD), how often do you meet on average?

4. (If yes to \#3) How satisfied are you with the support your (PD, APD, MSD) program coordinator is giving you?

5. On average, how many hours per month do you spend on administrative duties for your position as a (PD, APD, MSD)?

6. On average, how many hours per month do you spend on direct educational acivities for your position as a (PD, APD, MSD)?

7. On average, how many hours per week do you spend on: supervising residents, seeing your own patients, procedures/surgical cases, administrative tasks, non-administrative/non-clinical tasks i.e. research

8. How many hours of sleep do you get on an average: work night, weekend night

9. On average, how many hours per week do you spend on: strength training, mild intensity cardiac activity, moderate cardiac activity, high intensity cardiac activity

10. What type of exercise do you prefer (check all that apply): lift weights, run, walk, hike, swim, dance, aerobics, yoga, pilates, play a team sport, other (please specify)

11. Do you block off time for meditation and/or introspection?

12. (If yes to \#11) How frequently do you block off time for meditation and/or introspection?

13. Do you have any hobbies?

14. (If yes to \#12) How many hours per month do you spend on your hobby or hobbies?

15. (If yes to \#12) Please list your hobbies.

16. Do you have a significant other?

17. (If yes to \#16) Does your significant other work?

18. (If yes to \#16) Does your significant other have flexible hours (i.e., could easily adjust hours should an acute concern arise)?

19. Do you have children living at home?

20. (If yes to \#19) Are any of your children in kindergarten or younger?

21. (If yes to \#19) Are any of your children in elementary school?

22. (If yes to \#19) Are any of your children in middle school or high school?

23. How much time (hours) do you have 'to yourself' each day outside of work and family commitments?

24. How many weeks of inpatient or ER/emergency outpatient-related calls do you cover per year (including supervision of residents/fellows)?

25. On average, how often do you come in when not on call during a given 3-month period?

26. On average, how often do you stay late for an add-on case per month?

27. Do you receive a stipend for your function as (PD, APD, MSD)?

28. (If yes to \#27) What is your annual stipend for your function as a (PD, APD, MSD)?

29. Please list any other administrative tasks you perform for your department, if any.

30. Are you bringing administrative work home to finish at night or on weekends?

31. (If yes to \#30) On average, how many hours per week are you spending on administrative work at home or on weekends?

32. Are you bringing clinical work home to finish at night or on weekends?

33. (If yes to \#32) On average, how many hours per week are you spending on clinical work at home or on weekends?

34. Please answer the following questions (scale Never, Rarely, Sometimes, Frequently, Usually, Always):

a. Do you love your job?

b. Are you excited to get up and go to work in the morning?

c. Does teaching invigorate you?

35. Maslach Burnout Inventory: Educators Survey (www.mindgarden.com)

36. Please feel free to make note of any thoughts that could not be adequately expressed by the survey questions above.

Fig. 1 Benchmarking survey. The questions listed were emailed in survey format through the Association of University Professors of Ophthalmology listserve. 
Table 1 Summary of survey results. Unless otherwise indicated, results are listed as median (interquartile range)

\begin{tabular}{|c|c|c|c|}
\hline & $\operatorname{MSD}(n=13)$ & $\operatorname{APD}(n=7)$ & $\mathrm{PD}(n=32)$ \\
\hline Year served & $6(2.5-8.5)$ & $3(1-3)$ & $5(3-12)$ \\
\hline Program coordinator support & $85 \%$ & $71 \%$ & $100 \%$ \\
\hline Very satisfied with coordinator & $73 \%$ & $60 \%$ & $53 \%$ \\
\hline Monthly hours spent on position & $10(4-15)$ & $15(10-20)$ & $30(20-40)$ \\
\hline Weekly hours, direct patient care & $22.5(20-30)$ & $22.5(10-30)$ & $20(10-25)$ \\
\hline Weekly hours, procedures or surgery & $7(5-8)$ & $8(5-15)$ & $8(4.5-11)$ \\
\hline Weekly hours, resident supervision & $10(10-20)$ & $30(16-30)$ & $15(7-22)$ \\
\hline Weekly hours, administrative tasks & $8(8-10)$ & $6(5-10)$ & $10(7-18)$ \\
\hline Weekly hours, research/other & $2(2-4)$ & $3(1-5)$ & $2(1-5)$ \\
\hline Receipt of stipend & $62 \%$ & $57 \%$ & $88 \%$ \\
\hline Average stipend (\$) & $\$ 19,125$ & $\$ 18,250$ & $\$ 41,741$ \\
\hline Weeks of call coverage per year & $6(3-7)$ & $8(4-9)$ & $4.5(2-6.5)$ \\
\hline Hours sleep, weekday & 6.5 & 7 & 6.8 \\
\hline Hours sleep, weekend & 7 & 7 & 8 \\
\hline Perform exercise weekly & $100 \%$ & $71 \%$ & $84 \%$ \\
\hline Have children at home & $85 \%$ & $100 \%$ & $72 \%$ \\
\hline
\end{tabular}

Abbreviations: APD, associate program director; MSD, medical student director; PD, program director.

Table 2 Summary of survey results for combined groups

\begin{tabular}{|l|l|}
\hline & Combined groups \\
\hline Take clinical work home & $65 \%$ \\
\hline Weekly hours spent on clinical work at home & 4 \\
\hline Take administrative work home & $79 \%$ \\
\hline Weekly hours spent on administrative work at home & 5 \\
\hline Stay late for add-on cases & $58 \%$ \\
\hline Come in outside of call & $62 \%$ \\
\hline Block time for introspection/meditation & $19 \%$ \\
\hline Pursue hobbies & $73 \%$ \\
\hline Have a significant other & $100 \%$ \\
\hline Significant other works & $75 \%$ \\
\hline Have children living at home & $79 \%$ \\
\hline
\end{tabular}

All groups (medical student director, associate program director and program director) were combined for these results.

With rare exception (1 MSD, 1 APD, and 6 PD), survey respondents perform a variety of other tasks for their department ranging from nontitled educational activities, to financial, office, or hospital committee service. No respondents listed themselves as department chairs, but three self-identified as vice-chairs without further elucidation as to whether this was specifically related to education.

Eighty-one percent of all survey responders receive a stipend for their role(s); if performing more than one role, only a single answer counted toward the overall average with "yes" trumping "no." Upon subanalysis, $62 \%$ of MSD receive a role-related stipend, with an average annual stipend of $\$ 19,125 ; 57 \%$ of APD receive a stipend, with an average annual stipend of $\$ 18,250$. Eighty-eight percent of PD receive a stipend, with an average annual stipend of $\$ 41,741$. One PD did not list a discrete stipend but does receive $20 \%$ full-time effort support. Those PD who are also MSD did not receive stipends for their roles as MSD.

\section{Call Coverage}

Over the course of a year, an MSD spends a median of 6 weeks (3-7) covering call, an APD 8 weeks (4-9), and a PD 4.5 weeks (2-6.5); there is no statistically significant difference found between groups. 


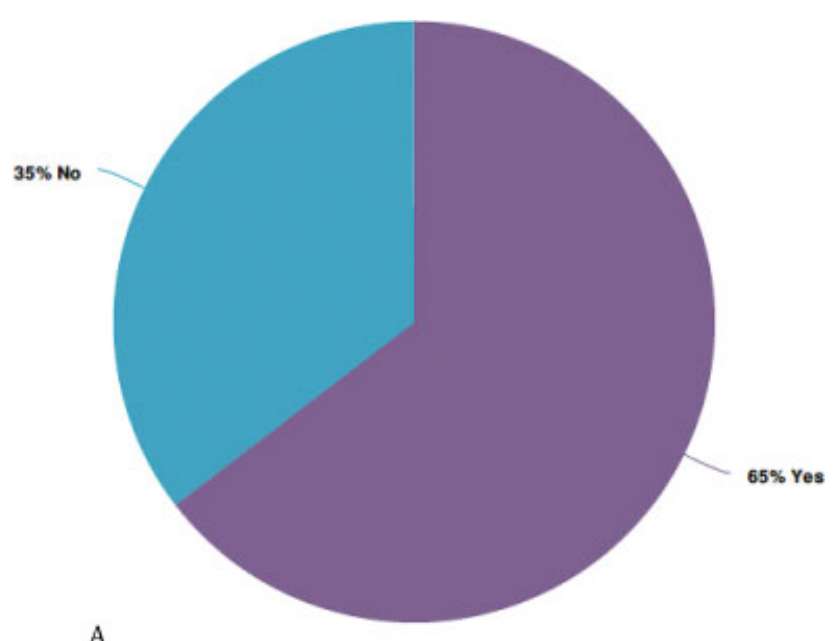

A

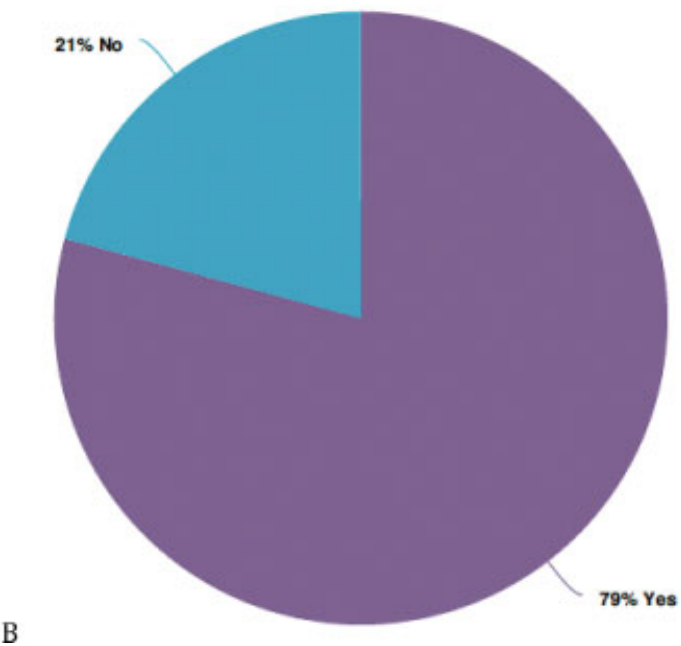

Fig. 2 Clinical and administrative work at home. (A) Sixty-five percent of respondents take clinical work home; (B) Seventy-nine percent of respondents take administrative work home.

Whether or not they are on call, when looking at all groups combined and examining a typical month, $42 \%$ never stay late for an add-on case, $42 \%$ stay late one to two times per month, $13 \%$ three to four times per month, and $4 \%$ at least five times per month. When not covering call, in any typical 3month period, $38 \%$ never come in for patient calls, $33 \%$ come in one to two times, $19 \%$ three to four times, and $10 \%$ at least five times (-Fig. 3). There is no statistically significant difference found between groups.

\section{Extracurricular Benchmarks}

\section{Sleep Hygiene}

The average MSD sleeps a median of 6.5 hours during the week, and 7 on weekends, an APD 7 hours for both, and a PD 6.8 during the week and 8 on weekends.

\section{Time for Self}

All groups have $\sim 1$ hour of time to themselves daily, without family or work commitments.

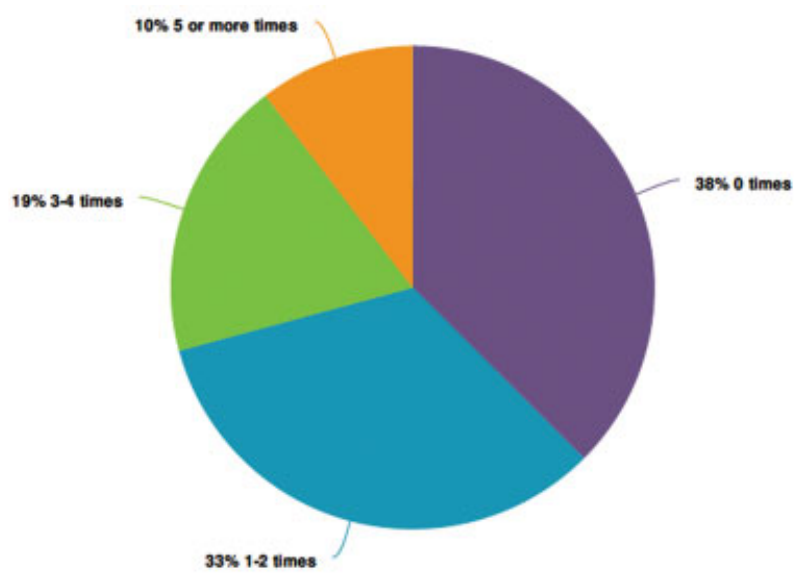

Fig. 3 Coming in when not on call. Respondents frequently contribute to patient care outside of routine workhours outside of the call schedule.

\section{Exercise}

One-hundred percent of MSD exercise in some fashion weekly, as opposed to $71 \%$ of APD and $84 \%$ of PD. The MSD, APD, and PD groups perform a median of 0 hours of strength training weekly (0-1 for each group); 31,29 , and 34\% of MSD, APD, and PD, respectively, perform strength training, with a combined average of 1 hour weekly. Cardiac activity was queried as mild, moderate, or high intensity. The MSD, APD, and PD groups perform a median of 0 hours ( $0-2), 1$ hour ( 0 5 ), and 0.1 hours ( $0-3)$ of mild cardiac activity, respectively; 0 hours ( $0-2$ ), 0 hours ( $0-2)$, and 1 hour ( $0-3)$ of moderate cardiac activity, respectively; and 0 hours (0-2), 1 hour (0-1), and 0 hours ( $0-2$ ) of high cardiac activity, respectively. There is no statistically significant difference in exercise frequency, performance of strength training, or intensity of cardiac activity between groups.

\section{Introspection and Meditation}

Only $19 \%$ of total respondents block time for introspection or meditation, the majority of these weekly (56\%) or daily (22\%).

\section{Hobbies}

In contrast, $73 \%$ enjoy a hobby, spending on average of 11 hours monthly on it. Of note, "hobby" was interpreted widely, including spending time with family, cooking, home maintenance, music and the arts, exercise, golfing, traveling, reading and video games, shopping, and flying.

\section{Family}

One-hundred percent of survey respondents have a significant other. Seventy-five percent of these significant others work, and of those significant others who work, 50\% have flexible hours. When performing subgroup analysis, there is no statistically significant difference found in terms of significant other work status or workhour flexibility.

In combined analysis, $79 \%$ have children who live at home. Of those children at home, $68 \%$ are in kindergarten or younger, $47 \%$ are in elementary school, and $23 \%$ are in middle school or high school. Among MSD, $85 \%$ have children at 
home; of those MSD with children, $100 \%$ have children in kindergarten or younger, $73 \%$ have children in elementary school, and $36 \%$ in middle school or higher. Among APD, 100\% have children living at home; $86 \%$ have children in kindergarten or younger, $57 \%$ have children in elementary school, and none have children in middle or high school. Seventytwo percent of PD have children living at home, 61\% have children in kindergarten or younger, $48 \%$ have children in elementary school, and 30\% have children in middle or high school. When performing subgroup analysis, there is no statistically significant difference in terms of children living at home, or in educational level of children living at home.

\section{Burnout Surveys}

Two surveys were used to query study subjects: a more positively-worded CTL survey and the MBI.

The CTL survey allows for a range of responses correlating to never, rarely, sometimes, frequently, usually, and always (-Fig. 4). It demonstrated, on average, that all subjects usually love their job, are invigorated by teaching, find that their position gives their medical career a sense of direction and meaning, brings satisfaction, suits subjective strengths, and connects them with their organization's values and similar peer leaders in the organization in a positive manner. Subjects frequently are excited to go to work in the morning. There is no statistically significant difference between MSD, $A P D$, and PD in survey responses.

The MBI for Educators asks a series of 22 questions designed to gauge burnout on three scales: emotional exhaustion (EE), depersonalization (DP), and personal accomplishment (PA). Subjects select from the following responses: never, a few times a year or less, once a month or less, a few times a month, once a week, a few times a week, and every day. Higher scores on the emotional exhaustion and depersonalization scales, and lower scores on the personal accomplishment scale, indicate greater degrees of burnout on a burnout continuum. As per the MBI group, there is no discrete cut-off representing "definitive burnout."

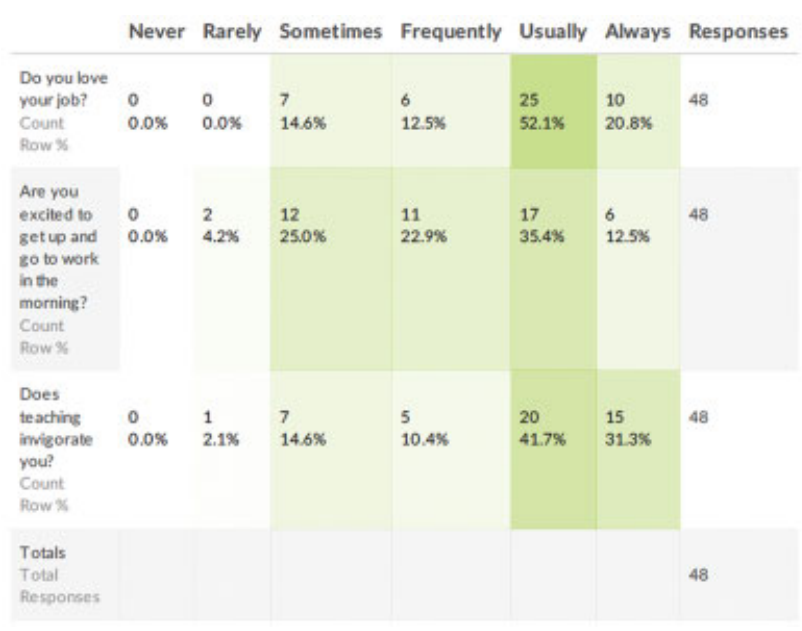

Fig. 4 Responses to the Center for Teaching and Learning (CTL) Survey. This heatmap demonstrates a generally positive attitude toward work.
Out of seven total, average Maslach scores for grouped subjects are 3 for EE, 1 for DP, and 5 for PA, respectively. When subdivided into leadership positions, there is no statistically significant difference between the groups.

\section{Conclusion}

Though this cross-sectional, anonymous benchmarking survey of MSD, APD, and PD on the AUPO listserve is limited by its response rate, the survey provides a clear marker of work responsibilities, extracurricular activities, family life, and a low tendency toward burnout. With rare exception, all leadership positions proved remarkably similar in terms of work expectations and home life.

All educational leaders balance a wide variety of workrelated duties, encompassing clinical, educational, research, and administrative tasks. For the vast majority, this includes administrative work beyond that of their leadership title. APD and MSD spend less time on tasks related to their title in a given month than PD, but typical weeks are fairly similar no matter the position. Perhaps this reflects bursts of PD output required over the course of several week periods, as opposed to more similarly aligned sustained output among all three groups. PD stipends are, on average, more than double that of MSD or APD, perhaps reflecting this difference in monthly output.

The majority reported adequate amounts of sleep. Though sleep needs are highly individualized, there is evidence that at least 7 hours of sleep nightly is acceptable. ${ }^{6}$ However, time spent exercising is relatively small. In comparison, a study of more than 3,000 Canadian physicians demonstrated an average of 4.7 hours of weekly exercise, ${ }^{7}$ and a study of nearly 500 American cardiologists demonstrated the majority exercised at least three times a week. ${ }^{8}$

A majority of respondents have children at home; the majority of these children are in kindergarten or younger. It is not clear whether child age is related to leadership being overall younger, or whether leadership tends to defer childbearing to a later age. Though $100 \%$ of respondents have a significant other, half of the $75 \%$ of working spouses have flexible hours. This would indicate that having a significant other with a flexible schedule (either not working or flexible workhours) is in some way associated with successful procurement and/or retention of educational leadership titles, perhaps related to the presence of young children.

The CTL survey demonstrates relatively positive job satisfaction across the board, with all leadership groups usually loving their job and teaching, finding meaning and satisfaction in their positions, and frequently being excited to go to work in the morning. Because this survey asks generally positively directed questions, it is interesting to compare it to the generally negatively directed questions of the MBI. It is reassuring that all groups were generally scoring low for DP and high for $\mathrm{PA}$, though moderately for $\mathrm{EE}(1 / 7,5 / 7$, and $3 / 7$, respectively). While there is no discrete cutoff for burnout according to the MBI, ${ }^{9}$ these scores appear to correlate with the positive responses on the CTL.

Ophthalmologists at large appear to have relatively higher rates of subjective or objective burnout than those reported 
here. A survey of 133 ophthalmologists in Quebec found 35\% "reported high levels of burnout and psychological distress," which was mainly attributed to shortage of ophthalmologists with increasing demand for the same, high team turnaround, and budgets. ${ }^{5}$ A survey of 297 ophthalmologists in India revealed that 25\% subjectively described themselves as nearly or being "burnt-out."3 According to the Medscape Ophthalmologist Lifestyle, Happiness \& Burnout Report 2019, 34\% are suffering from burnout (lower than overall physician average of $44 \%$ ), with similar rates of overall depression compared with the average physician (11\% colloquially and $3 \%$ clinically depressed). ${ }^{2}$ A large number of factors appear to contribute to physician burnout, most prominently bureaucratic tasks, government regulations, increasing computerization, and reimbursement. ${ }^{2}$ Other fields have also examined burnout in educational leadership with variable subjective and objective indicators. A positive burnout response was noted in up to $27 \%$ of surveyed Family Medicine PD, ${ }^{10} 21 \%$ of Anesthesia PD, ${ }^{11}$ up to $25 \%$ of General Surgery PD, ${ }^{12} 29 \%$ of IM PD, ${ }^{13}$ and $62 \%$ of IM MSD (clerkship directors). ${ }^{14}$

A modified MBI survey of 101 chairs of academic ophthalmology departments demonstrated $9 \%$ to have burnout, though only $9 \%$ showed no characteristics of burnout on any portion of the modified MBI, which in turn was based on a paper examining burnout among gynecology leadership. ${ }^{4}$ It is impossible to precisely compare with the ophthalmology chair survey, which used a modified and presumably shortened version of the MBI and thus would have different score cutoffs. However, if one assumes that dividing maximal answer scales into thirds is a reasonable indication of low, moderate, or high EE, DP, and PA, one can attempt to compare with the ophthalmology chair survey. Accordingly, there were no respondents meeting high levels of EE and DP with low PA in this study, and thus none demonstrating burnout. Additionally, 25\% of respondents showed low levels of EE and DP and high PA, or the equivalent of no burnout characteristics whatsoever. However, it is important to emphasize "that there is no definitive score that 'proves' a person is 'burned out"' according to formal MBI guidelines. ${ }^{9}$

Our survey results correlate with a high sense of job satisfaction and career meaning on the CTL. Thus, it would appear that significant involvement in ophthalmic academic life is either a predictor of physician resilience and wellbeing, an incubator of it, or some combination of the two. A 2017 meta-analysis examining individual versus organizational efforts to reduce burnout in physicians demonstrated both types of efforts could allow for statistically significant improvement in burnout rates; however, organizational efforts were more widely impactful. ${ }^{15}$ For example, efforts at re-examining schedules/templates, improving teamwork and communication, and a sense of increased job control allowed for larger burnout impact than individual changes in behavior or mindfulness. ${ }^{15}$ In the cohort studied herein, one might theorize an increased baseline sense of control over individual roles and communication with members of the academic and administrative team (including coordinators, trainees, chairmen and the medical school). One might also consider purposeful schedule management to help keep burnout rates low. Two comments from the survey demonstrate realistic frustration balanced with continued love of the position. One respondent reports that secretarial tasks such as creating schedules and ensuring faculty, and trainees complete assignments and form submissions to the GME or ACGME offices "take away time from focusing on the bigger picture and making meaningful changes to the program." Another respondent finds that while s/he "[loves] my job and [gets] satisfaction from it, it often feels there is a wall of obstruction keeping me from doing it and doing it well. The burnout in other faculty make doing my job harder - the teaching suffers and a few soldiers carry on. The institution/ department is revenue centered. The time for teaching is shrinking while the stress is increasing so people are not doing a good job. They recognize it but there are no good solutions."

There are two limitations to this study: the survey response rate and the difficult balance of anonymity. The survey response rate (22\%) likely reflects limitations on survey delivery by listserv policy, as well as the length of the survey. In an effort to maintain complete anonymity in a relatively small educational leadership group, there were no survey queries regarding age, gender, region, program size, and medical school size. Questions of gender have become particularly critical recently, and at this point would be particularly relevant to pursue in future study-specifically, subjective perceptions regarding gender and work life. As gender was not queried, it is unclear whether the relative similarities among all leadership positions exist despite gender imbalances between positions, or because most subjects are of the same gender. There were at least two respondents who keenly felt the pressure of gender disparities. One remarked that any expressed frustrations in the survey were due to "the staggering expectations that are placed upon young mothers in academic medicine," as opposed to her specific educational leadership position; though she wished she could be less clinically active while her children are young, she feels there is no "mechanism in academic medicine to enable this without penalizing [her] career." Another respondent wrote that "women are more likely to not have a supportive flexible partner, and are more likely to do more "free" work, getting compensated less for things like [being] PD or even for their clinical work." A third respondent of unclear gender commented that his/her "career was pretty much on hold during the years when [2] children were more dependent on [him/her] for care...Support systems for parents can also help prevent burnout and enhance job performance." While this survey was not created to capture these questions, and because the survey truly did preserve anonymity, an additional follow-up query regarding gender is not feasible with the current data. A future survey regarding gender dynamics in educational leadership would be timely and critical.

In conclusion, this benchmark survey demonstrates that MSD, APD, and PD are intensively involved in both their work and home lives, with a seemingly high correlation of sense of worth both personally and in their careers. 


\section{Financial Disclosures}

None.

\section{Funding}

The Department of Ophthalmology at Columbia University Irving Medical Center is supported by an unrestricted grant from Research to Prevent Blindness.

\section{Conflict of Interest}

Dr. De Moraes reports grants and personal fees from Novartis, grants from Heidelberg Engineering, personal fees and non-financial support from Carl Zeiss, nonfinancial support from Topcon, personal fees from Galimedix, personal fees from Belite, personal fees and nonfinancial support from Reichert, grants and personal fees from Perfuse Therapeutics, outside the submitted work.

\section{References}

1 Mental health, World Health Organization. https://www. who.int/mental_health/evidence/burn-out/en/ Accessed April 3, 2020

2 Medscape Ophthalmologist Lifestyle. Happiness \& Burnout Report 2019. https://www.medscape.com/slideshow/2019-lifestyle-ophthalmologist-6011133\#1 Published 2019. Accessed October 24, 2021

3 Nair AG, Jain P, Agarwal A, Jain V. Work satisfaction, burnout and gender-based inequalities among ophthalmologists in India: a survey. Work 2017;56(02):221-228
4 Cruz OA, Pole CJ, Thomas SM. Burnout in chairs of academic departments of ophthalmology. Ophthalmology 2007;114(12): 2350-2355

5 Viviers S, Lachance L, Maranda MF, Ménard C. Burnout, psychological distress, and overwork: the case of Quebec's ophthalmologists. Can J Ophthalmol 2008;43(05):535-546

6 Eugene AR, Masiak J. The neuroprotective aspects of sleep. MEDtube Sci 2015;3(01):35-40

7 Frank E, Segura C. Health practices of Canadian physicians. Can Fam Physician 2009;55(08):810-811.e7

8 Abuissa H, Lavie C, Spertus J, O'Keefe J Jr. Personal health habits of American cardiologists. Am J Cardiol 2006;97(07):1093-1096

9 Maslach C, Jackson SE, Leiter MP. Maslach Burnout Inventory Manual. 4th Edition; Mind Garden; 2018;29:37 www.mindgarden. com

10 Porter M, Hagan H, Klassen R, Yang Y, Seehusen DA, Carek PJ. Burnout and resiliency among family medicine program directors. Fam Med 2018;50(02):106-112

11 De Oliveira GS Jr, Almeida MD, Ahmad S, Fitzgerald PC, McCarthy RJ. Anesthesiology residency program director burnout. J Clin Anesth 2011;23(03):176-182

12 Anderson KD, Mavis BE, Dean RE. Feeling the stress: perceptions of burnout among general surgery program directors. Curr Surg 2000;57(01):46-50

13 West CP, Halvorsen AJ, Swenson SL, McDonald FS. Burnout and distress among internal medicine program directors: results of a national survey. J Gen Intern Med 2013;28(08):1056-1063

14 Dyrbye LN, Shanafelt TD, Thomas MR, Durning SJ. Brief observation: a national study of burnout among internal medicine clerkship directors. Am J Med 2009;122(03):310-312

15 Panagioti M, Panagopoulou E, Bower P, et al. Controlled interventions to reduce burnout in physicians: a systematic review and meta-analysis. JAMA Intern Med 2017;177(02):195-205 